
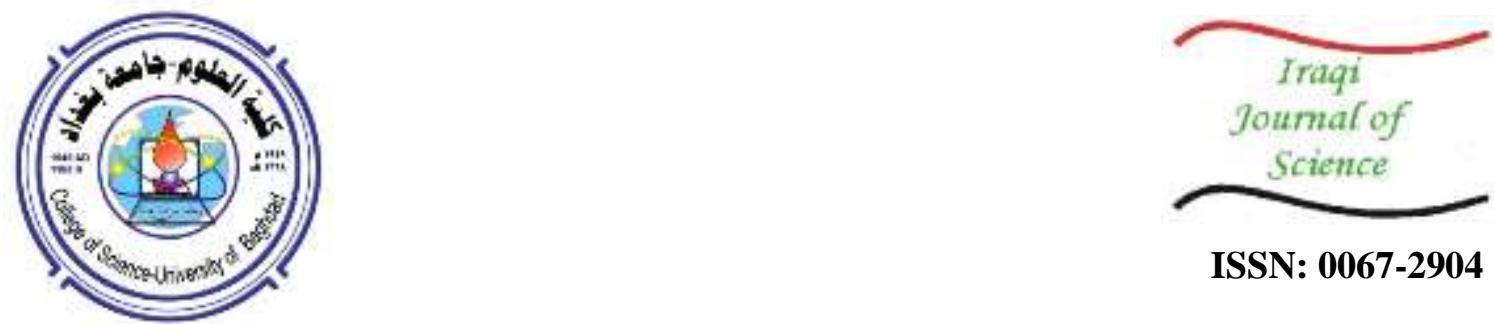

ISSN: 0067-2904

\title{
The Role of Fructophilic Lactic Acid Bacteria in the Restoration of Infected Wounds and IL-17 Level in Rabbits
}

\author{
Shahad Mansour Salman*, Ghada Mohammed Saleh \\ Department of Biology, College of Science, University of Baghdad, Baghdad, Iraq
}

Received: $10 / 5 / 2019 \quad$ Accepted: 17/7/2019

\begin{abstract}
Fructophilic lactic acid bacteria (FLAB) isolated from honeybee's nectar stomach represent an important source of antimicrobial substances that has been focused on nowadays. In this study, these FLABs were tested for their antibacterial activity in vivo as well as the detection of Interleukine -17 in the serum of rabbits ingested with FLAB isolates. Fructobacillus fructosus FH1, Fructobacillus fructosus FH8 and Lactobacillus kunkeei SHGH-7 FLAB isolates were used against wound infections caused by Pseudomonas aeruginosa and Staphylococcus aureus (MRSA) in rabbit skin . Enzyme linked sorbent immunoassay (ELISA) was used to detect the levels of Interleukine-17 in the sera of rabbits ingested with these three FLAB isolates. The results showed that the time of wound healing process was shorter in the FLAB treated wounds when compared to control untreated wounds with a significant difference at $p \leq 0.01$. Histopathological examination of wounds treated with FLAB isolates showed normal thickness in skin layers with no pathological effect, as well as tissue repair and presence of new blood vessels when compared to pathogen groups that were infected with pathogenic bacteria without any treatment, which showed hyperplasia with necrosis in tissue. Results of the FLAB-ingested groups showed an increase in the level of IL-17 when compared to the control with no statistical significance $(\mathrm{P} \leq 0.05)$. To the best of our knowledge, this is the first study on using FLAB microorganisms in the treatment of infected wounds.
\end{abstract}

Keywords: Honeybee, Fructophilic lactic acid bacteria, nectar stomach, infected wound treatment.

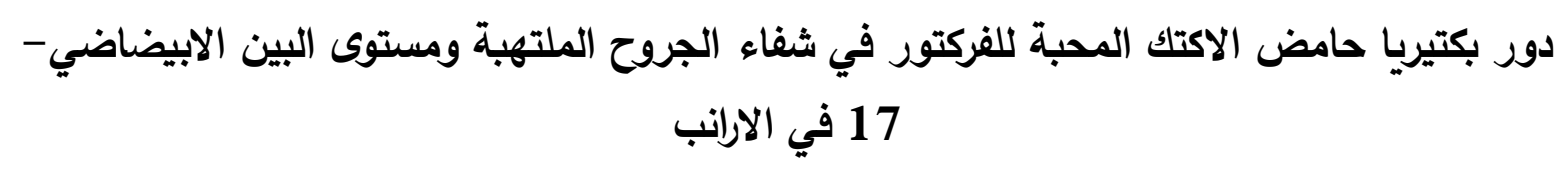

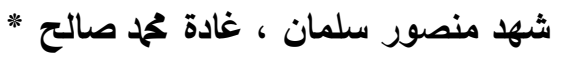

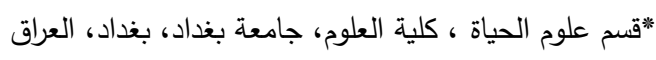

الخلاصة

بكتيريا الاكتك اسد المحبة للفركتوز (FLAB) المعزولة من رحيق معدة النحل يمثل مصدرا مهما للمواد

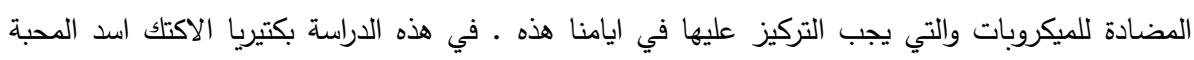

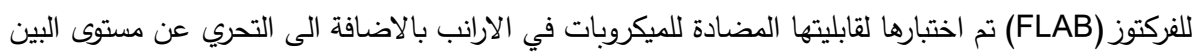

الابيضاضي السابع عشر IL

*Email:ghada90m@gmail.com 


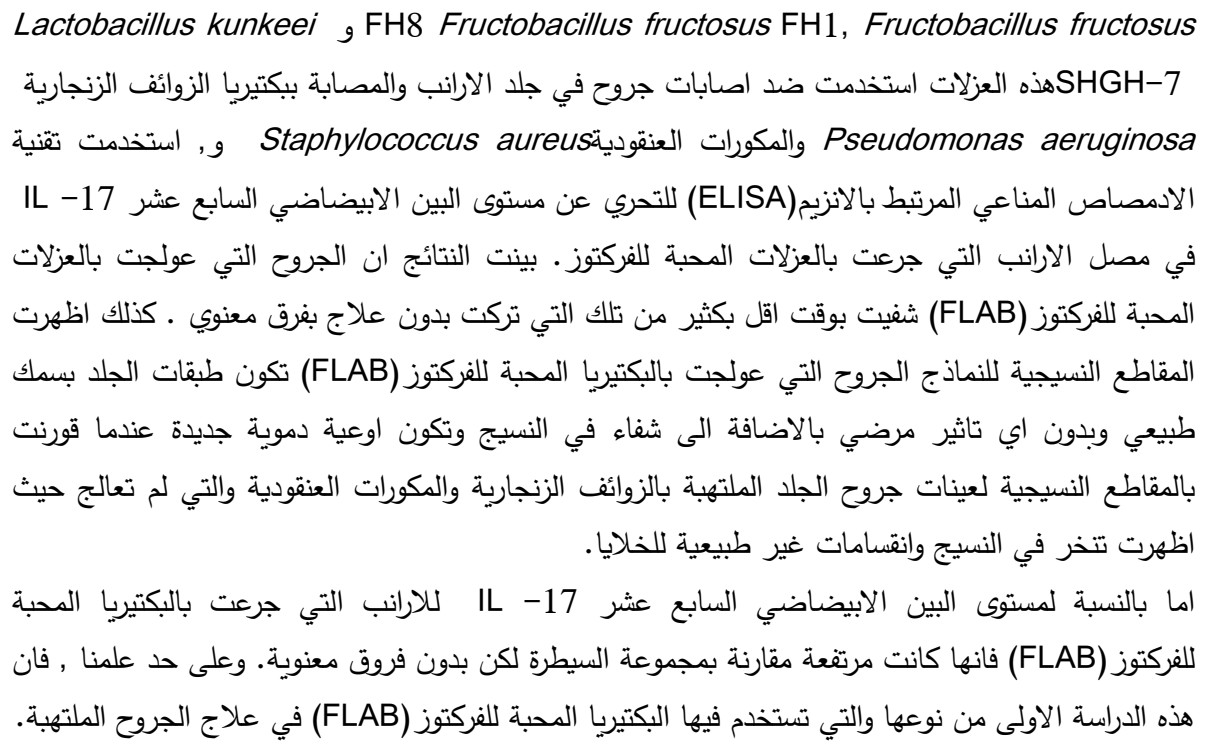

\section{Introduction}

Honeybees are very important insects especially for humans, because of their increased value not only for honey production but also for their importance economically and as an ecosystem manager [1]. A special group of lactic acid bacteria was described as fructophilic lactic acid bacteria (FLAB). This special group was isolated from honeybee's nectar stomach, which is considered as a fructoserich niche [2,3]. In general, FLAB prefer fructose instead of glucose as a carbon source. These bacteria have great importance for honeybee's defense against pathogens and have an important role in honey production, and this may explain why honey has been regarded as an antimicrobial agent throughout humans' history. Fructobacillus fructosus and Lactobacillus kunkeei are part of FLAB microorganisms $[4,5]$.

Increasing antibiotic resistance encourages the researchers to search for new antimicrobial alternatives that maybe found in natural products as alternative tools against wound infections, which is important in human and animal infections [6, 7]. Researchers showed that FLAB symbionts isolated from the nectar stomach of honeybee are remarkable players in the antimicrobial activity of honey by the production of antimicrobial materials and that they can be used with honey for wound treatment. The healing characteristics of honey with the antimicrobial substances produced from FLAB have an antibacterial effect on most wound pathogens. FLAB metabolites work synergistically and form abundant bioactive substances that are the key for many future application of FLAB in wound restoration [8].

The pro inflammatory cytokine IL-17 is an important therapeutic target for a growing number of chronic inflammatory diseases [9]. Interleukin-17 expressing cells include not only leukocytes but epithelial cells, mesothelial cells, vascular endothelial cells, keratinocytes and fibroblasts. In experimental animal models, IL-17 provides protection against respiratory infections [10] by inducing production of a variety of cytokines/chemokines from bronchial epithelial cells, airway fibroblasts and smooth muscle cells. This promotes the recruitment of both neutrophils and memory Th1 cells to the airways [11]. The aim of our study was to evaluate the effect of FLAB isolates in the management of infected wounds and detect the level of serum IL-17 in rabbits ingested with FLAB isolates.

\section{Materials and methods}

\section{Study groups of animals}

Thirteen healthy male albino rabbits with an average weight of $1.5 \mathrm{~kg}$ were included. Animals were housed in individual cages with food and water in a controlled room temperature $\left(22 \pm 2^{\circ} \mathrm{C}\right)$. An acclimatization period of 7 days was observed before starting the experiment to allow for adaptation to the experimental conditions [12]. Rabbits were divided into four groups: first, control group (2 rabbits); second, pathogen group ( 2 rabbits); third, FLAB group (3 rabbits) and fourth, Test group (6 rabbits).

\section{Surgical incision assessment}

Before surgery, rabbits were locally anesthetized with a subcutaneous injection of $2 \%$ lidocaine at a dose of $0.5 \mathrm{ml}$.The dorsal region (near the insertion of the scapula) was shaved using an electric 
clipper. After outlining the skin, the region was prepared antiseptically; two cutaneous incisions $(1 \mathrm{~cm}$ in diameter) were induced on the dorsal midline using a sterile scalpel as shown in Figure-1 and as previously described [13].

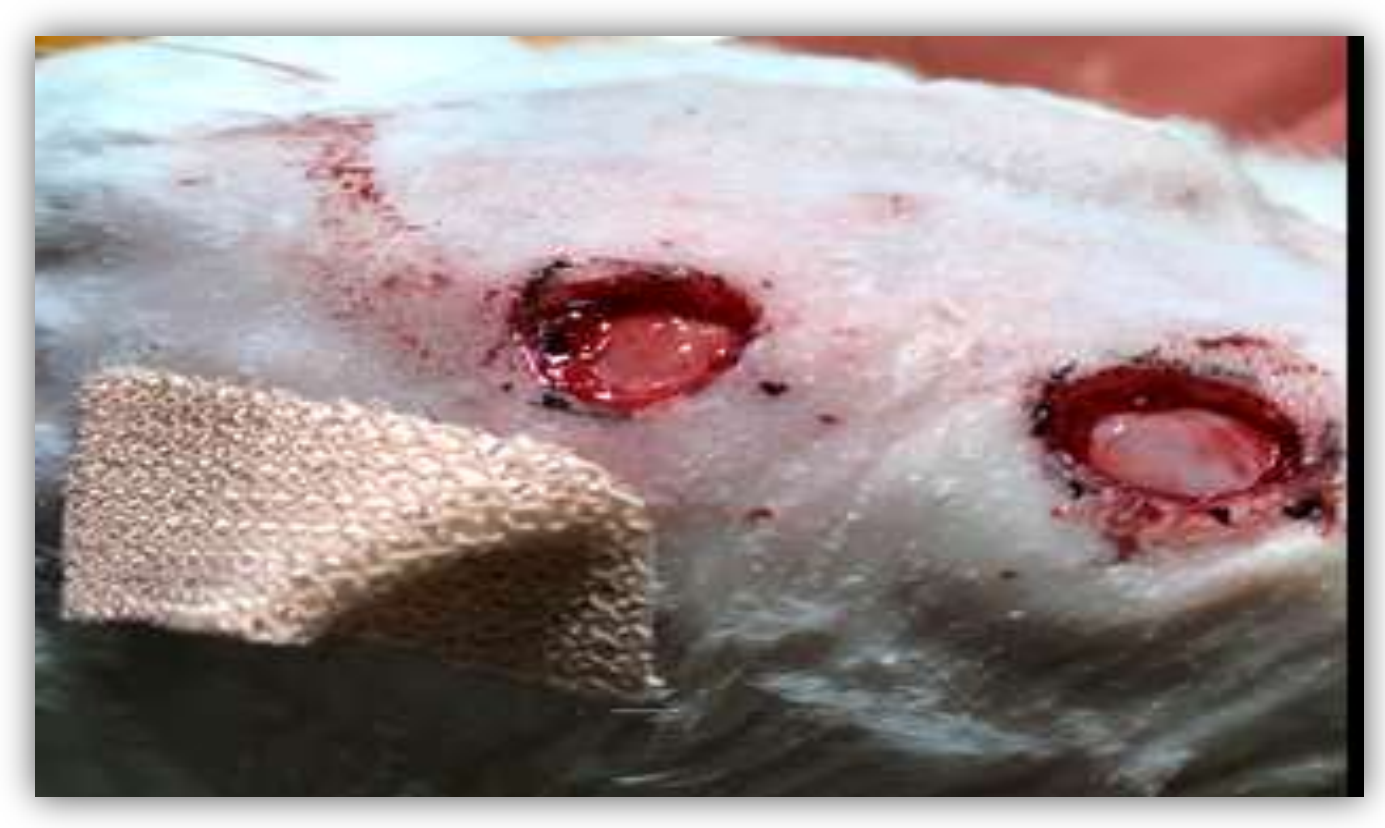

Figure 1-Cutaneous incisions $(1 \mathrm{~cm}$ in diameter) induced on the dorsal midline of the rabbit using a sterile scalpel to test antibacterial activity of FLAB in vivo.

\section{Treatment of wounds by FLAB - honey combination}

Three previously identified FLAB isolates [14], Fructobacillus fructosus FH1 (MH327257.1), Fructobacillus fructosus FH8 (LC278384.1) and Lactobacillus kunkeei SHGH-7 (LC278386.1) were used against wound infections caused by Pseudomonas aeruginosa and Staphylococcus aureus (MRSA) pathogenic isolates in rabbit skin (the infection was confirmed by isolating the same pathogen that started the infection).

Each isolate of FLAB was mixed with natural honey (directly collected from beehive by a specialist and sterilized at $112{ }^{\circ} \mathrm{C}$ for $15 \mathrm{~min}$, for the killing of microbial life in honey ) to form a gel

like substance (total cell count of FLAB $=10^{9} \mathrm{CFU} / \mathrm{gm}$ honey) [7]. The gel was applied directly to the moist infected wound and covered by a dressing band [15]. These treatments were performed twice a week. Thirteen rabbits separated into four groups of the study were included; the first group was the control group and consisted of two rabbits, not exposed to any pathogenic bacteria or treatment by FLAB. The second group was the pathogen group, which included two rabbits, one injected locally in the skin of the dorsal line by $P$. aeruginosa and the other was injected by $S$. aureus (MRSA). These two rabbits did not undergo any kind of treatment by FLAB. The third group was FLAB group, which consisted of three rabbits, the incisions of each one were treated by one bacterial type of FLAB $(F$. fructosus HN-F1, F. fructosus HN-F8 or L. kunkeeei HN-L7, respectively). The fourth group was the Test group, which included six rabbits injected locally by pathogens. Test 1 consisted of three rabbits infected by $P$. aeruginosa and Test 2 of three rabbits infected by $S$. aureus. The incisions were taken after the Test rabbits had shown inflammation signs in the injection site, such as fever, redness, swelling, and pain. After that, the Test groups were treated by FLAB bacteria (HN-F1, HN-F8 and HN-L7) from Day zero (Day zero here means 2-3 days after each inflammation has occurred for each pathogen used) until they were completely healed, and a biopsy was taken from each rabbit.

All wounds were protected with a sterile gauze $\left(1 \mathrm{~cm}^{2}\right)$. Morphological examination and wounds diameter were measured from day zero until reaching the day of complete healing.

\section{Histological assessment}

A biopsy was taken for all rabbits in the study after sedation of the rabbits using the same anesthetic protocol mentioned previously. A skin section covering the central area and wound edges of 
$0.5 \mathrm{~mm}$ were cut using a sterile scalpel. The skin fragments were fixed in $10 \%$ formalin solution for 48 hours. The histopathological protocol included paraffinized skin sections $(5 \mu \mathrm{m})$ which were stained using hematoxylin-eosin (HE) and examined under a light microscope by a professional pathologist [16].

\section{Treatment with FLAB ingestion}

Thirteen albino rabbits were divided into four groups. The first three rabbits were treated with $F$. fructosus (HN-F1), the second three were treated with $F$. fructosus (HN-F8), and the other three were treated with L. kunkeei (HN-L7). Two rabbits were used as the control group and the other two for the pathogen group, which was ingested with $P$. aeruginosa.

Fructophilic lactic acid bacteria were activated by culturing in MRS broth supplemented with $2 \%$ fructose and $0.1 \% \mathrm{~L}$-cysteine. It was incubated at $28-30^{\circ} \mathrm{C}$ with anaerobic conditions for 48 hours [17]. The FLAB cells were harvested ( $5000 \mathrm{rpm} / \mathrm{min}$ for $15 \mathrm{~min}$ ) and washed twice by normal saline $0.9 \%$. 8

Each inoculate included $10 \mathrm{CFU} / 1 \mathrm{~mL}$ of FLAB bacteria given to the rabbits by ingestion using a metal stomach tube (directly to the stomach to prevent the rabbits from spilling it out of the mouth) for three days a week for three weeks. Blood samples were taken from all groups of rabbits by heart puncture method after sedation by thiopentone $(1 \mathrm{~g} / 20 \mathrm{ml})$ with a volume of $0.5 \mathrm{ml}$ for each rabbit. The blood was centrifuged $(5000 \mathrm{rpm} / \mathrm{min}, 10 \mathrm{~min})$ and serum was then transferred to clean sterilized plane tubes to detect the IL-17 level.

\section{Enzyme-linked immunosorbent assay (ELISA) for rabbit interleukin-17}

Interleukin-17 was detected by sandwich ELISA in the serum of rabbits that had been ingested with FLAB, pathogenic bacteria and in the control group. ELISA was used based on biotin double antibody sandwich technology to assay rabbit IL-17. Interleukin-17 was added to wells that are pre-coated with IL-17 monoclonal antibody and then incubated. After incubation, anti-IL-17 antibodies labeled with biotin were added to bind with streptavidin-HRP, forming an immune complex. Unbound enzymes were removed and, after incubation and washing, the substrates A and B were added. The solution turned blue and changed to yellow with the effect of acid added at last. The shades of the solution and the concentration of rabbit IL-17 were positively correlated.

\section{Statistical analysis}

The data were analyzed using SPSS IBM version 20 IBM. Differences between study groups and assays were analyzed by Mean, Standard Error, ANOVA, LSD and One-sample T-test used to calculate the significant. Differences with P-values of $p \leq 0.05$ were considered statistically significant.

\section{Results and Discussion}

\section{Antibacterial activity and healing process of FLAB in vivo}

In this study, wounds with $1 \mathrm{~cm}$ diameter were made on the skin of rabbits to test the activity of three types of FLAB isolates on wounds management. The results showed that the control wound was completely healed in 21 days (Figure-2) which is in general a longer time to heal when compared to the other groups of the study. The pathogen group 1, which was infected by $P$. aeruginosa without any treatment by FLAB, showed inflammation signs and the rabbit died (on day 9) before the end of the experiment (Figure-2). The pathogen group 2, which was infected by $S$. aureus without any treatment by FLAB, also showed inflammation signs that continued even after the end of the experiment. The wound was closed but still internally infected, showing abscess when it was opened (Figure-2). Pathogen groups 1 and 2 showed no significant difference when compared to the control group, as shown in Table-1. 


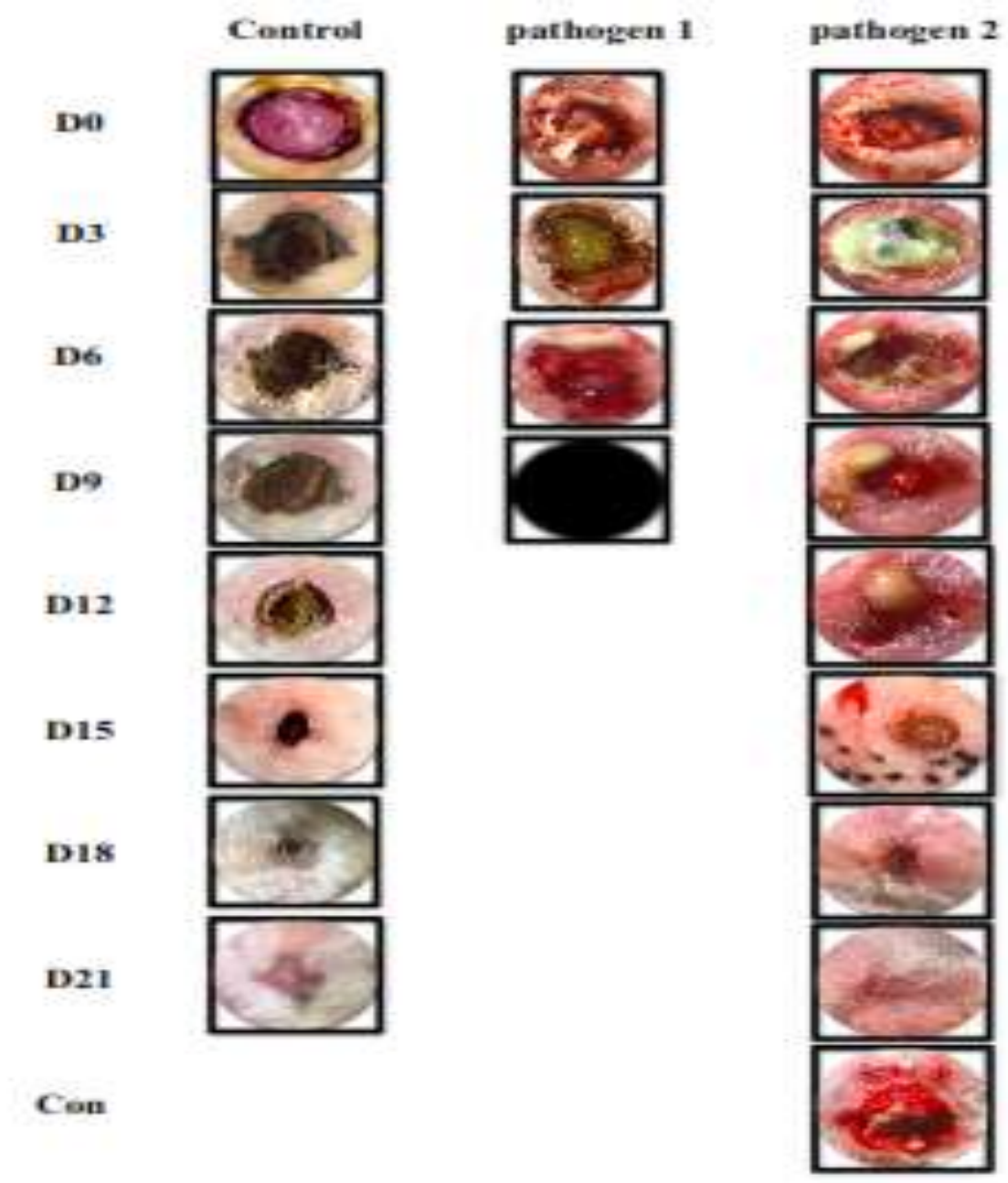

Figure 2-Macroscopic evolution of the healing process of the wounds in control group and pathogen 1 group which was infected with P.aeruginosa and Pathogen 2 group which was infected with S.aureus at all-time points (D,Days/Con, ContinuousDead animal).

Table 1-Healing of wounds (measured in centimeters, $\mathrm{cm}$ ) using FLAB in vivo.

\begin{tabular}{|c|c|c|c|c|c|c|c|c|c|}
\hline Specimen & D 0 & D 3 & D 6 & D 9 & D 12 & D 15 & D 18 & D 21 & \\
\hline Control & $1 \mathrm{~cm}$ & 0.9 & 0.8 & 0.75 & 0.6 & 0.4 & 0.2 & 0 & \\
\hline $\begin{array}{c}\text { Pathogen } 1 \\
\text { P. aeruginosa }\end{array}$ & $1 \mathrm{~cm}$ & 1.25 & 1 & Die & & & & & \\
\hline $\begin{array}{l}\text { Pathogen } 2 \\
\text { S. aureus }\end{array}$ & $1 \mathrm{~cm}$ & 1.4 & 1.2 & 1 & 0.6 & 0.5 & 0.3 & 0 & con \\
\hline FLAB & $\begin{array}{ll}\text { HN-F1 } & 1 \mathrm{~cm} \\
\text { HN-L7 } & 1 \mathrm{~cm}\end{array}$ & $\begin{array}{l}0.8 \\
0.9\end{array}$ & $\begin{array}{l}0.6 \\
0.7\end{array}$ & $\begin{array}{l}0.5 \\
0.4\end{array}$ & $\begin{array}{l}0.3 \\
0.2\end{array}$ & $\begin{array}{l}0 \\
0\end{array}$ & & & \\
\hline $\begin{array}{c}\text { Test (1) } \\
\text { P. aeruginosa }\end{array}$ & $\begin{array}{ll}\text { HN-F1 } & 1 \mathrm{~cm} \\
\text { HN-L7 } & 1 \mathrm{~cm}\end{array}$ & $\begin{array}{c}1 \\
0.9\end{array}$ & $\begin{array}{l}0.7 \\
0.7\end{array}$ & $\begin{array}{l}0.5 \\
0.4\end{array}$ & $\begin{array}{c}0.2 \\
0\end{array}$ & 0 & & & \\
\hline $\begin{array}{l}\text { Test (2) } \\
\text { S. aureus }\end{array}$ & $\begin{array}{ll}\text { HN-F1 } & 1 \mathrm{~cm} \\
\text { HN-L7 } & 1 \mathrm{~cm}\end{array}$ & $\begin{array}{l}0.9 \\
0.9\end{array}$ & $\begin{array}{l}0.7 \\
0.5\end{array}$ & $\begin{array}{l}0.5 \\
0.2\end{array}$ & $\begin{array}{c}0.2 \\
0\end{array}$ & 0 & & & \\
\hline
\end{tabular}

HN-F1: Honeybees nectar Fructobacillus fructosus

HN-L7: Honeybees nectar Lactobacillus kunkeei

D: measurement day of the wound diameter

Con: continuous inflammation after the end of the experiment 0 : Complete recovery of the skin. 
Wounds treated by FLAB isolates (HN-F1, HN-F8 and HN-L7) healed faster, i.e. at 12-15 days (Figure-3), showing significant differences at $(\mathrm{P} \leq 0.01)$ as compared to the control and pathogens groups. In the Test 1 group (wounds infected by $P$. aeruginosa and then treated with FLAB isolates, HN-F1, HN-F8 and HN-L7 separately), before treatment with FLAB (after 2-3 days of the start of the inflammation), the wounds showed redness, swelling, pain and pus exudate from inflammation as well as severe bleeding during the process of taking a skin section. After treatment with FLAB, the wounds showed good healing and complete repair in 12-18 days (Fig. 4), which was significantly different at $(\mathrm{P} \leq 0.01)$ as compared to the control and pathogens groups (Table-1). The inflammation signs began to disappear during the continuous treatment with FLAB. Test 2 groups (wounds infected by $S$. aureus and then treated with FLAB isolates) treated as previous. After treatment with FLAB, the wounds showed good healing and complete repair in 12-15 days (Figures-4,5) which was significantly different $(\mathrm{P} \leq 0.01)$ as compared to the control and pathogens groups (Table-1). The inflammation signs began to disappear during the continuous treatment with FLAB.

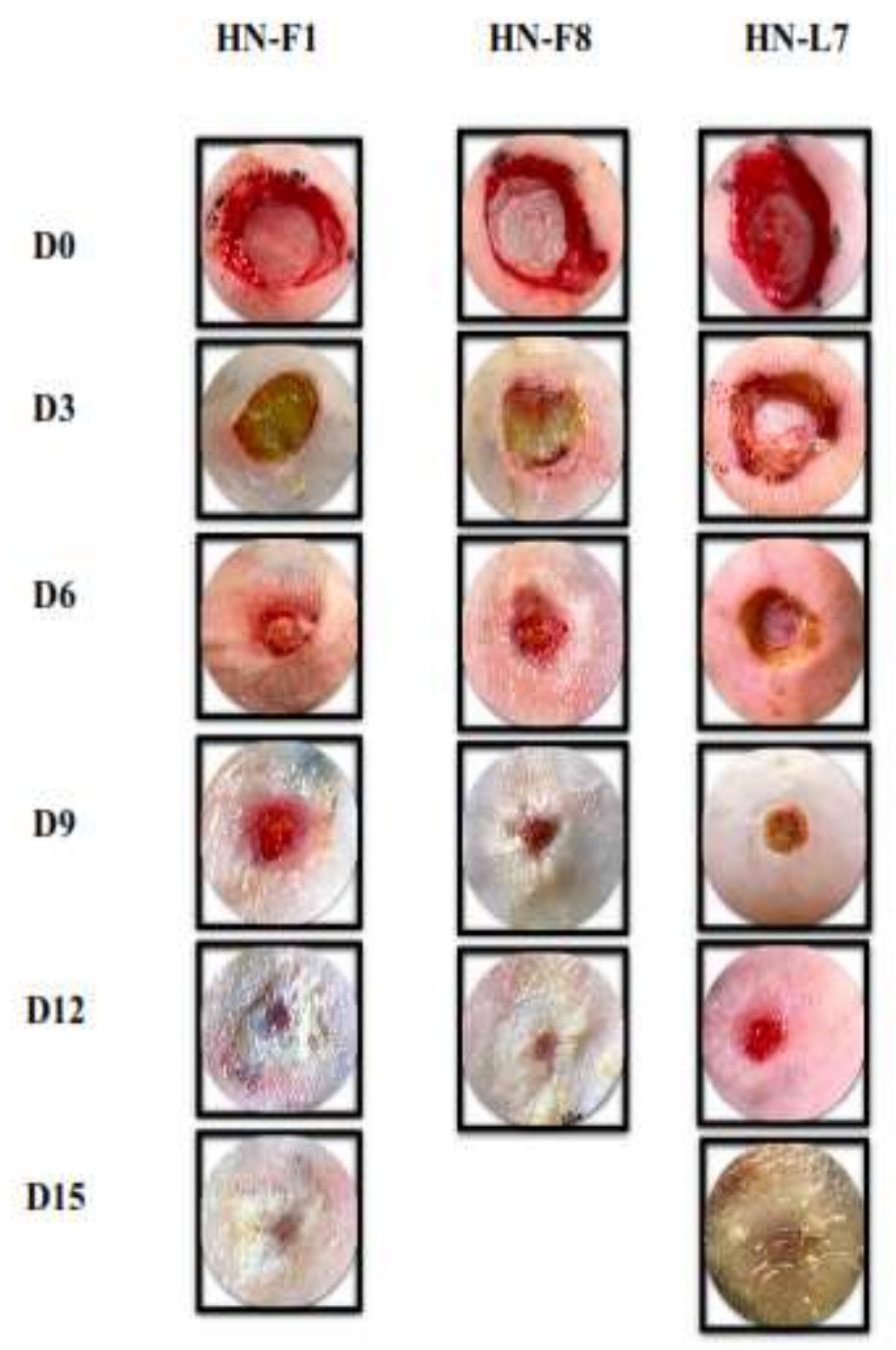

Figure 3-Macroscopic evolution of the healing process of the wounds in FLAB group treated with FLAB bacteria at all-time points (D,Days). 


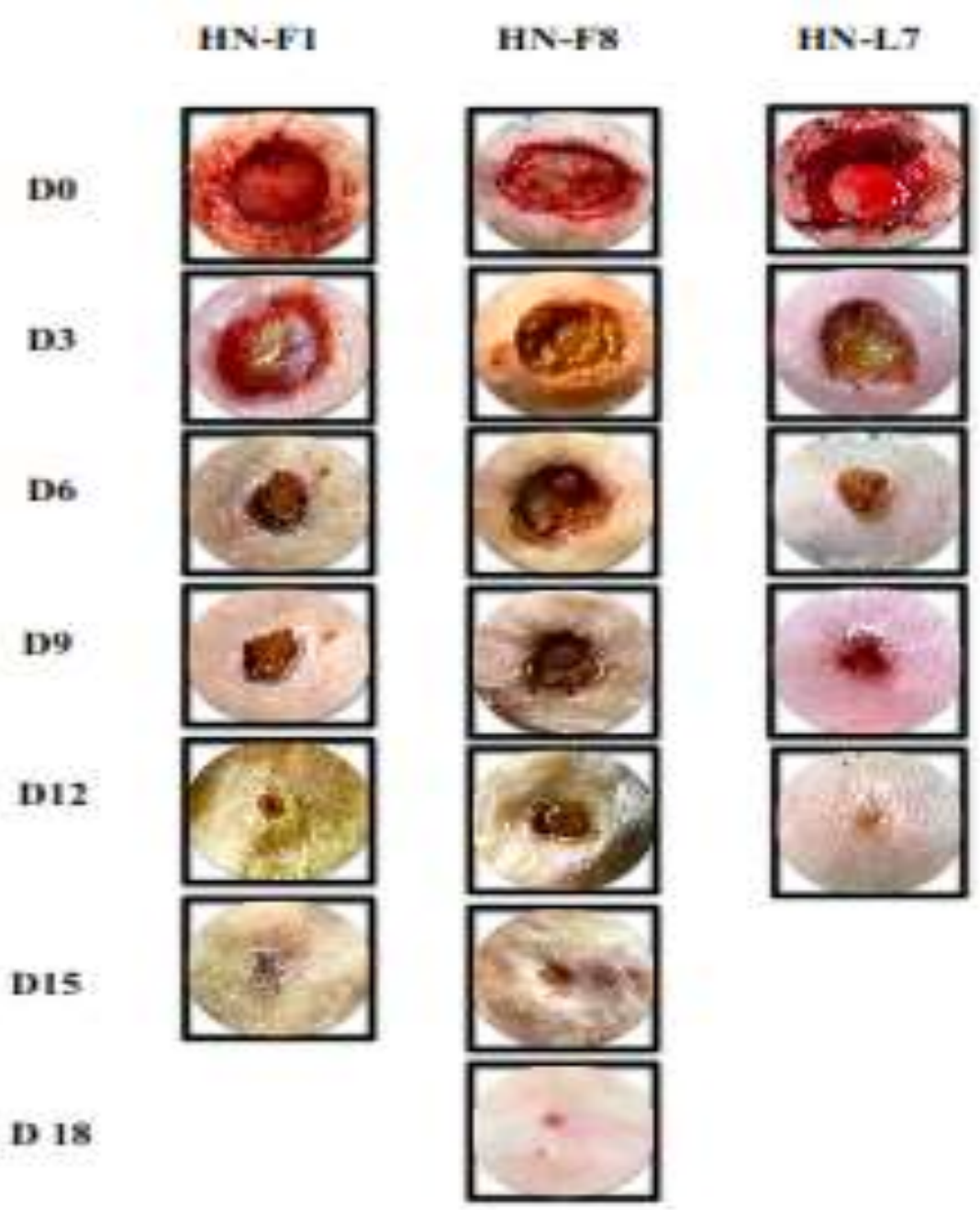

Figure 4-Macroscopic evolution of the healing process of the wounds in Test 1 group infected with P.aeruginosa and treated with FLAB bacteria (HN-F1, HN-F8, and HN-L7) at all-time points (D,Days). 


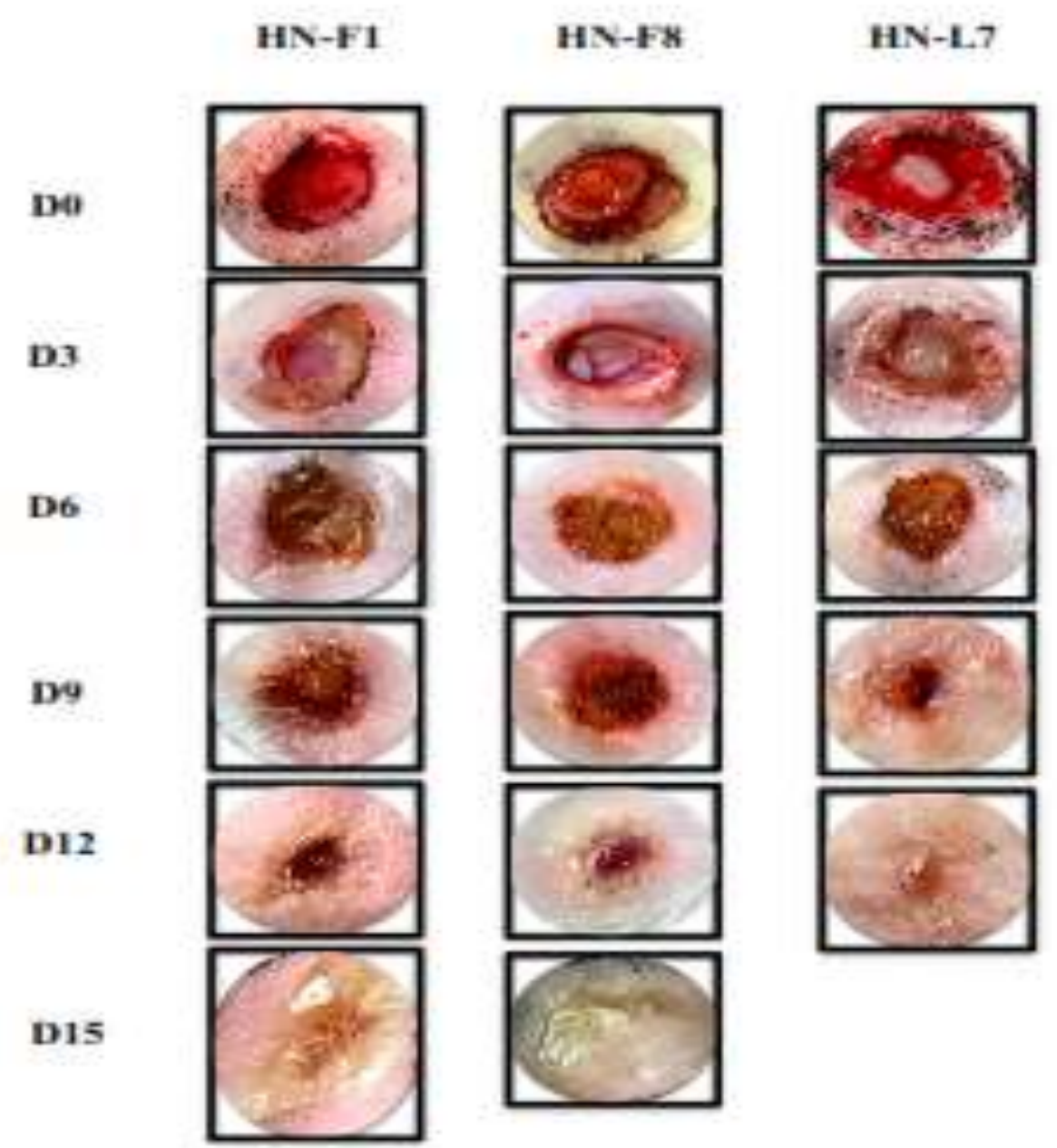

Figure 5-Macroscopic evolution of the healing process of the wounds in Test 2 group infected with Staphylococcus aureus and treated with FLAB bacteria (HN-F1, HN-F8, and HN-L7) at all-time points (D,Days).

The traditional treatment of wounds is by using antiseptic dressing such as iodine, silver, or polyhexanide [18]. These treatments are associated with environmental and patient-related hazards and having high cost for the patient and health sector. Due to the increasing antibiotic resistance [19] and biofilm formation in the wound, it's better to use an environmental-friendly wound dressing made from honey with viable FLAB, which is non-toxic and have antimicrobial properties to treat chronic wound that are poly-microbial in nature, such as Staphylococcus, Enterococcus, and Pseudomonas species [20,21]. In this study, and for the first time in Iraq, the novel honeybee fructophilic lactic acid bacteria (FLAB) were used in wound management. A related study was conducted in Sweden in 2016 to detect the effects of honeybees symbiotic LAB isolates on wounds pathogens in horses. This study showed that all LAB isolates inhibited pathogens in vitro and in vivo and all horses healed almost completely at the end of the experiment [17,7]. As shown in Table-1, the FLAB group generally showed better and earlier healing than the control group, which indicates a positive effect of FLAB in wound area, which might be caused by production of hydrogen peroxide (H2O2) in small amounts by FLAB which is required for optimal wound healing [22].

Test 1 and Test 2 groups that were infected by $P$. aeruginosa and $S$. aureus and treated by FLAB isolates healed faster and better than than the pathogen group, that did not undergo any treatment. This indicates that FLAB has been activated in the presence of pathogenic bacteria, $P$. aeruginosa and $S$. aureus, to produce extracellular metabolites that inhibited these pathogens from causing infection. Fast healing results from the ability of FLAB to produce different extracellular metabolites during microbial stress, such as enzymes and lysozyme [23]. These metabolites act on different pathogens, some of them are bactericidal and some are bacteriostatic, and have different mechanisms of action, 
such as DNA synthesis and interfering with cell membrane permeability [17]. Also, FLAB in general are able to change the growth environment by rapidly producing high levels of organic acids, such as lactic acid, acetic acid, and formic acid which could cause high acid /low $\mathrm{pH}$ environment and form a hostile environment for wound pathogens $[24,5]$. Some studies showed that antimicrobial peptide bee defensin-1 was produced by FLAB, which alters the expression of a specific protein in S. aureus [25]. Because of the broad spectrum of antimicrobial substances that are produced by FLAB, it is recommended to use them in infected wounds management [7].

\section{Histological examination}

In the control group, the histopathological sections of rabbit showed normal skin layers. Skin layers, like epidermis and dermis, were present in normal thickness and the skin lesion started to repair normally, also the keratin layer was normal in thickness as shown in Figure-6a. The histopathological examination of the FLAB group showed no clear pathological lesion in the skin. The rabbits wounds that treated by F. fructosus (HN-F1) bacteria, showed a normal healing and normal skin layers.
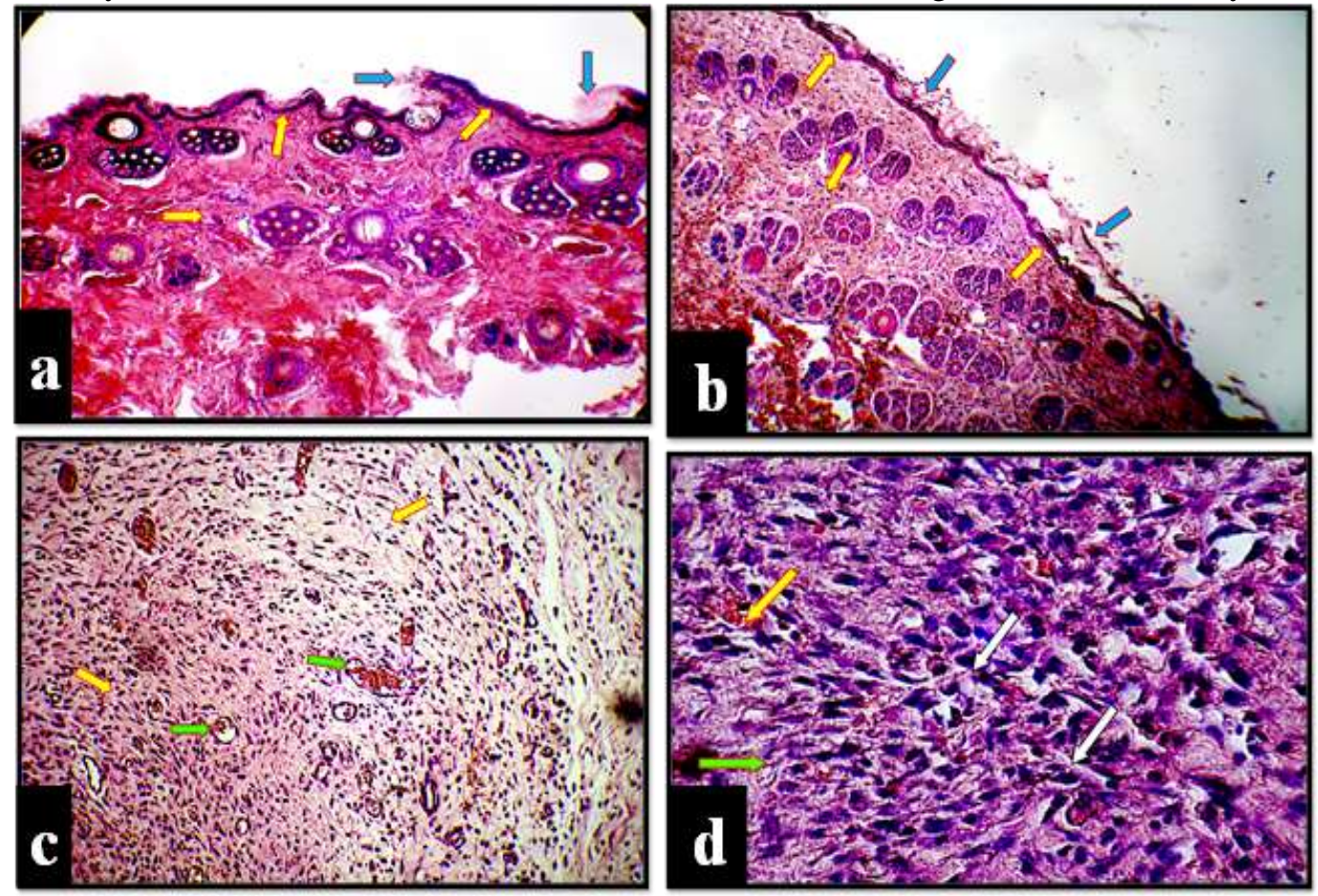

Figure 6-Photomicroscopy of the control wounds represented by the letter (a) which showed a normal thickness of keratin (blue arrow) and skin layers (yellow arrow). The letters (b) and (c) which represent normal wounds and those treated with FLAB isolate F. fructosus HN-F1 showed normal keratin aggregation (b) (blue arrow), normal epidermis and dermis (b) (yellow arrow), granulation tissue formation characterized by swarming of fibroblasts (c) (yellow arrow), and new congested blood vessels (c) (green arrow). The letter (d) represents normal wounds treated with L. kunkeei HNL7 which showed congested blood vessels (yellow arrow), fibrous C.T proliferation (green arrow) and mononuclear cell infiltration (gray arrow). (H\&E 40X magnification).

The keratin layer was normal in thickness when compared to that in the pathogen groups. Epidermis and dermis were normal in thickness (Figure-6b). There was an aggregation of fibroblast and congestion of new blood vessels formed in the granulation tissue (Figure-6c). These results were similar to those for the rabbit wounds treated with F. fructosus (HN-F8). Also, rabbits wounds treated by L. kunkeei (HN-L7) bacteria showed congested blood vessels and granulation with fibrous connective tissue proliferation (Figure-6d). In the pathogens groups that infected by P. aeruginosa and $\mathrm{S}$. aureus that did not undergo any treatment, the histopathological examination at the site of the infected area was characterized by hyperkeratinization of skin. Hyperplasia of the epidermis layer gave a finger-like appearance extended to the dermis layer, indicating a severe increase in the reproduction rate of stratified squamous epithelium cells, severe suppurative reaction and necrosis of epidermis and dermis, with inflammatory reactions that extend to the muscular layer of the skin (Fig. 
7 e,f). The test groups, infected with P. aeruginosa and S. aureus and then treated with FLAB bacteria, showed a normal thickness of keratin aggregation with normal epidermis and dermis layers when compared to pathogens groups without treatment with FALB (Figure-7 g,i). A mix of inflammatory infiltrates in the dermis was shown, which was composed of mononuclear cells with neutrophils. Also, there was an aggregation of mononuclear cells around congested blood vessels between the muscle fibers. Granulation tissue formation was characterized by aggregation of fibrocytes with newly formed blood vessels and keratinocytes, along with lymphocytes and macrophages (Figure-7 h,j). The general effect of FLAB on pathogenic P. aeruginosa and S. aureus was almost similar on the wound healing process from the histopathological examination.
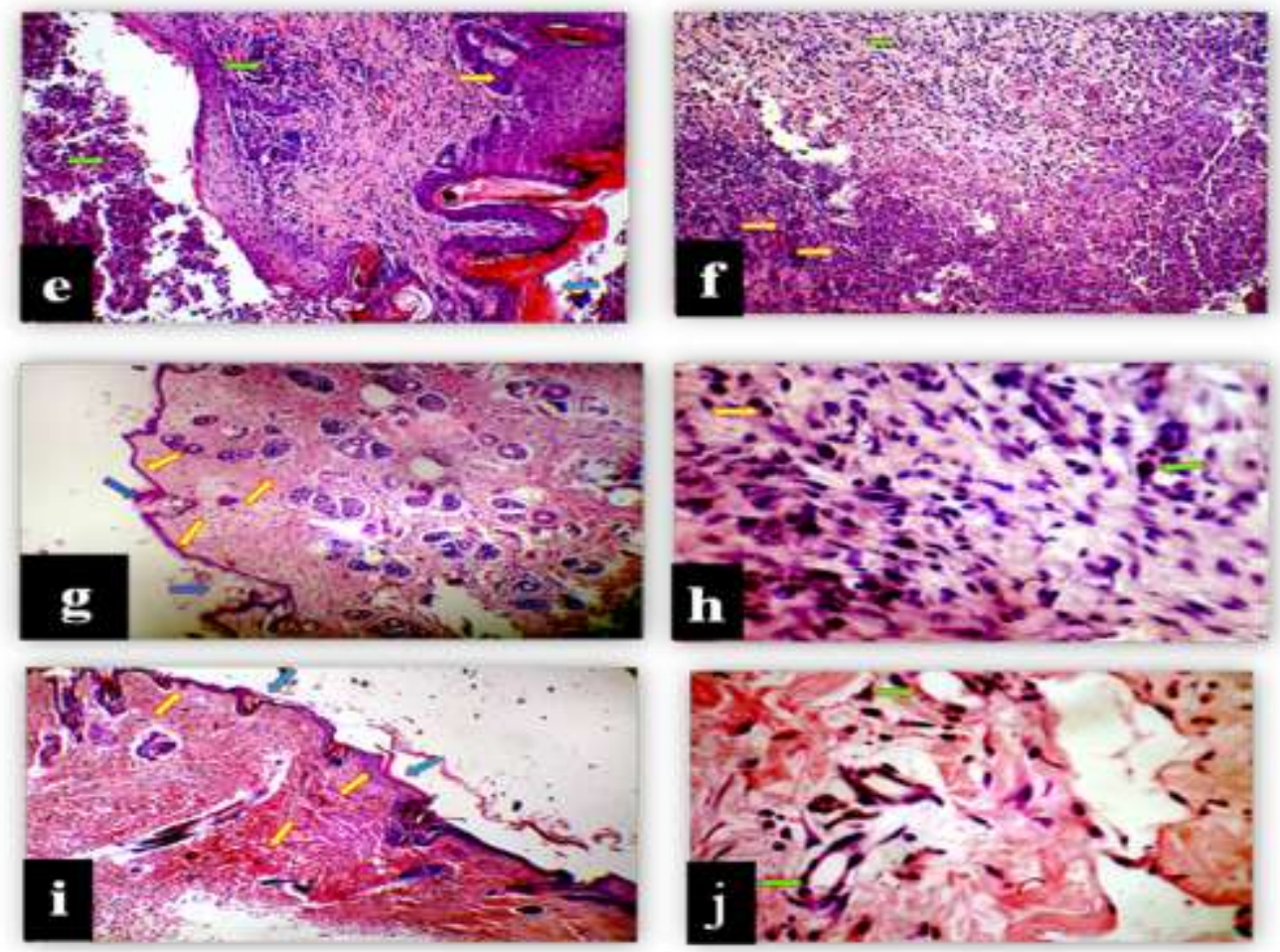

Figure 7-Photomicroscopy of the pathogen wound infected with $S$. aureus represented by the letter (e), which showed hyperkeratinization (blue arrow) with hyperplasia of the epidermis (yellow arrow), necrosis of dermis layer, and neutrophil infiltration (green arrow). The letter (f) represents wound infected with $P$. aeruginosa, which showed infiltration of inflammatory cells in the dermis layer (green arrow) and suppurative inflammation in subcutaneous tissue (yellow arrow). The letters (g) and (h) represent wounds infected with $S$. aureus and then treated with FLAB isolates; $F$. fructosus HN-F1 (g) which showed normal thickness of keratin aggregation (blue arrow) with normal layers of epidermis and dermis layer (yellow arrow); L. kunkeei HN-L7 (h) which showed no clear pathological lesion with mild presence of macrophages (green arrow) and lymphocytes (yellow arrow). The letters (i) and (j) represent wounds infected with $P$. aeruginosa and then treated with FLAB isolates; $F$. fructosus HN-F1 (i) which showed normal keratin aggregation (blue arrow) with normal epidermis and dermis layer (yellow arrow) and L. kunkeei HN-L7 (j) that showed no clear pathological lesion with newly formed B.V. formation (green arrow). (H\&E 40X magnification).

\section{Effects of the ingestion of FLAB on Interleukin-17 level}

In this study, each kind of FLAB (HN-F1,HN-F8 and HN-L7) bacteria was ingested to groups of rabbits to test the effect of FLAB on IL-17 in rabbits. The level of IL-17 was measured after three days from the end of the experiment. IL-17 level increased in the test group that was ingested with FLAB for three weeks when compared to the control group, but it did not show any statistical significance. The results also demonstrated a high level of IL-17 in the group of rabbits that ingested the pathogenic bacteria $P$. aeruginosa when compared to FLAB and control groups as shown in Table-2. 
Table 2- Rabbit Interleukin-17 levels in the ingested rabbit groups and control group

\begin{tabular}{|c|c|c|}
\hline Strains & $\begin{array}{c}\text { IL-17 con. ng/ml } \\
\text { Mean } \pm \text { SE }\end{array}$ & \multirow{2}{*}{ Sig. } \\
\cline { 1 - 2 } Control & $113.07 \pm 10.5$ & \multirow{2}{*}{0.857} \\
\cline { 1 - 2 } Fructobacillus fructosus HN-F1 & $138.55 \pm 11.9$ & \\
\cline { 1 - 2 } Fructobacillus fructosus HN-F8 & $151.01 \pm 10.8$ & \\
\cline { 1 - 2 } Lactobacillus kunkeei HN-L7 & $204.08 \pm 16.5$ & \\
\hline Pseudomonas aeruginosa & $264.06 \pm 24.3$ & \\
\hline
\end{tabular}

*(P< 0.05), Con: concentration; SE: Standard Error

IL-17 is considered as an important cytokine that induces neutrophil-mediated inflammatory responses. When cells are activated through IL-17-mediated signaling, they produce chemokines including CXCL-8 and IL-8 alomg with cytokines including granulocyte colony-, resulting in generation and accumulation of neutrophils in the infected sites. Immunoregulatory functions other than neutrophil induction seem to be involved in IL-17 mediated protection against other infections. Diverse extracellular bacteria, such as $P$. aeruginosa, have been reported to induce IL-17 expression at an early stage of infection [26]. However, the opposite took place in the present study, where FLAB ingested rabbits showed lower IL-17 levels than the pathogen ingested group, which can be explained by immune regulation rather than tissue damage, leading to enhanced body health. The statistical nonsignificance maybe related to the number of experimental rabbits or ages, as well as the number and concentration of FLAB ingested to the animals.

\section{Conclusion}

FLAB- honey combination is recommended to be used in the near future for wound management, such as human and animal wounds which are colonized by significant pathogenic bacteria. The pathogen-infected and not infected skin wounds treated with FLAB isolates showed better and faster healing than control skin wounds and pathogen infected wounds without treatment. Interleukin-17 level in sera of rabbits ingested with FLAB showed an increase compared to the control group that was not ingested. Furthermore, IL-17 level was also increased in the rabbits ingested with pathogenic bacteria compared to FLAB treated groups and control group, but it was not significant.

\section{References}

1. VanEngelsdorp, D. and Meixner, M. D. 2010. A historical review of managed honey bee populations in Europe and the United States and the factors that may affect them. J. Invert. Path., 103: S80-S95.

2. Porcellato, D., Frantzen, C., Rangberg, A., Umu, O. C., Gabrielsen, C., Nes, I. F., Amdam, G. V and Diep, D. B. 2015. Draft genome sequence of Lactobacillus kunkeei AR114 isolated from honey bee gut. Genome Announc., 3: 144-15.

3. Neveling, D. P., Endo, A and Dicks, L. M. 2012. Fructophilic Lactobacillus kunkeei and Lactobacillus brevis isolated from fresh flowers, bees and bee-hives. Curr Microbiol., 65: 507515.

4. Endo, A., Irisawa, T., Futagawa-Endo, Y., Sonomoto, K., Itoh, K., Takano, K., Okada, S. and Dicks, L. M. T. 2011. Fructobacillus tropaeoli sp. nov., a novel fructophilic lactic acid bacterium isolated from a flower. Int J Syst Evol Microbiol, 61: 898-902.

5. Olofsson, T. C., Butler, E., Markowicz, P., Lindholm, C., Larsson, L and Vasquez, A. 2014. Lactic acid bacterial symbionts in honeybees - an unknown key to honeys antimicrobial and therapeutic activities. Int Wound J., 13(5): 668-679.

6. Udwary, D. W., Gontang, E. A., Jones, A. C., Jones, C. S., Schultz, A.W., Winter, J. M., Yang, J. Y., Beauchemin, N., Capson, T. L., Clark, B. R., Esquenazi, E., Eustáquio, A. S., Freel, K., Gerwick, L., Gerwick, W. H., Gonzalez, D., Liu, W. T., Malloy, K. L., Maloney, K. N., Nett, M., Nunnery, J. K., Penn, K., Prieto-Davo, A., Simmons, T. L., Weitz, S., Wilson, M. C., Tisa, L. S., Dorrestein, P. C and Moore, B. S. 2011. Significant natural product biosynthetic potential of 
actinorhizal symbionts of the genus Frankia, as revealed by comparative genomic and proteomic analyses. Appl Environ Microbiol .,77: 3617 - 25.

7. Olofsson, T. C., Butler, E., Lindholm, C., Nilson, B., Michanek, P and Va squez, A. 2016. Fighting Off Wound Pathogens in Horses with Honeybee Lactic Acid Bacteria. Curr Microbial., 73: 463-473.

8. Patrucia, S and Hutu, I. 2013. Economic benefits of using prebiotic and probiotic products as supplements in stimulation feeds administered to bee colonies. Anim Sci: Turkish J Vet., 37:1-9.

9. Miossec, P. ; Korn,T and Kuchroo, V.K.. 2009. Interleukin-17 and type 17 helper T cells. N. Engl. J. Med., 361. 888-898.

10. Khader, S. A and Cooper, A. M. 2008. IL-23 and IL-17 in tuberculosis. Cytokine., 41: 79-83.

11. Hodge, G., Nairn, J., Holmes, M., Reynolds, P. N and Hodge, S. 2007. Increased intracellular T helper 1 proinflammatory cytokine production in peripheral blood, bronchoalveolar lavage and intraepithelial T-cells of COPD subjects. Clin. Exp. Immunol., 150: 22-29.

12. Yamada, A. L. M., Carvalho, A. M., Oliveira, P. G. G., Felisbino, S. L., Queiroz, D. L., Watanabe, M. J., Hussni, C. A and Alves, A. L. G. 2012. Plasma rico em plaquetas no tratamento de lesões condrais articulares induzidas experimentalmente em eqüinos: avaliação clínica, macroscópica, histológica e histoquímica. Arq Bras Med Vet Zootec., 64 (2): 323-32.

13. Abegão, K. G. B., Bracale, B. N., Del m, I. G., dos Santos, E. S., Laposy, C.B., Nai, G. A., Giuffrida, R and Nogueira R. M. 2015. Effects of heterologous platelet-rich plasma gel on standardized dermal wound healing in rabbits. Acta Cirúrgica Brasileira., 30(3): 209-215.

14. Shahad M. S. and Ghada M.S. 2018. Fructophilic lactic acid bacteria symbionts in honeybees - a key role to antimicrobial activities. Journal of Pharmacy and Biological Sciences., 13 (1): 58-62.

15. Forsgren, E., Olofsson, T. C., Vásquez, A and Fries, I. 2010. Novel lactic acid bacteria inhibiting Paenibacillus larvae in honey bee larvae. Apidologie., 42: 99-108.

16. Allen, D.C. and Cameron, R. I. 2004. Histopathology specimens: clinical, pathological and laboratory aspects (London.: Springer 2004).

17. Butler, E., Oien, R. F., Lindholm, C., Olofsson, T. C., Nilson, B and Va' squez, A. 2014. A pilot study investigating lactic acid bacterial symbionts from the honeybee in inhibiting human chronic wound pathogens. Int Wound J., 13(5): 729-737.

18. Keast, D and Lindholm, C. 2012. Practice development: ensuring that the correct antimicrobial dressing is selected. Wounds Int., 3: 2-7.

19. Sen, C. K., Gordillo, G. M., Roy, S., Kirsner, R., Lambert, L., Hunt, T. K., Gottrup, F., Gurtner, G. C and Longaker, M. T. 2009. Human skin wounds: a major and snowballing threat to public health and the economy. Wound Repair Regen., 17: 763-71.

20. Dowd, S. E., Sun, Y., Secor, P. R., Rhoads, D. D., Wolcott, B. M., James, G. A and Wolcott, R. D. 2008. Survey of bacterial diversity in chronic wounds using pyrosequencing, DGGE, and full ribosome shotgun sequencing. BMC Microbiol., 8:43.

21. Öien, R. F and Åkesson, N. 2012. Bacterial cultures, rapid strep test, and antibiotic treatment in infected hard to heal ulcers in primary care. Scand J Prim Health Care., 30: 254-8.

22. Loo, A. E. K., Wong, Y. T., Ho, R., Wasser, M., Du, T., Ng, W. T and Halliwell, B. 2012. Effects of hydrogen peroxide on wound healing in mice in relation to oxidative damage. PLoS ONE., 7: 49215.

23. Butler, E., Alsterfjord, M., Olofsson, T. C., Karlsson, C., Malmstrom, J and Vasquez, A. 2013. Proteins of novel lactic acid bacteria from Apis mellifera mellifera: an insight into the production of known extra-cellular proteins during microbial stress. BMC Microbial.,13: 235.

24. Yoshiyama, M., Wu, M., Sugimura, Y., Takaya, N., Kimoto-Nira, H and Suzuki, C. 2013. Inhibition of Paenibacillus larvae by lactic acid bacteria isolated from fermented materials. $J$ Invert Pathol., 112: 62-67.

25. Jenkins, R., Burton, $\mathrm{N}$ and Cooper, R. 2011. Effect of manuka honey on the expression of universal stress protein A in methicillin-resistant Staphylococcus aureus. Int J Antimicrob Agents., 37: 373-6.

26. Dubin, P. J and Kolls, J. K. 2007. IL-23 mediates inflammatory responses to mucoid Pseudomonas aeruginosa lung infection in mice. Am. J. Physiol. Lung Cell. Mol. Physiol., 292: 519-528. 